\title{
Lens Epithelial Surface Disorders in Exfoliation Syndrome: A Scanning and Transmission Electron Microscopy Study
}

\author{
Konstantina N. Sorkou ${ }^{a}$ b $\quad$ Maria Eleni Manthou ${ }^{a}$ Soultana Meditskou ${ }^{a}$ \\ Ioannis T. Tsinopoulos $^{b}$ Nikolaos Ziakas $^{\text {b }}$ Kokkona Kouzi-Koliakou $^{a}$ \\ a Laboratory of Histology and Embryology, Medical School, Aristotle University of Thessaloniki, Thessaloniki, Greece; \\ b 2nd Department of Ophthalmology, Medical School, Aristotle University of Thessaloniki, Thessaloniki, Greece
}

\section{Keywords \\ Exfoliation syndrome · Age-related cataract · Anterior lens capsule $\cdot$ Scanning electron microscopy $\cdot$ Transmission electron microscopy}

\begin{abstract}
Background: Hydrodissection was recently reported to occur more easily in patients with exfoliation syndrome (XFS). Transmission electron microscopy (TEM) studies have already revealed alterations of the lens epithelial cells (LECs) and their apical membrane towards the lens fibers. Objective: The aim of this work was to examine the three-dimensional appearance of the lens epithelium in patients with XFS. Methods: Fourteen patients with senile cataract, 7 of whom had XFS, were included. Anterior lens capsules (aLCs) were obtained with continuous curvilinear capsulorrhexis (CCC) during phacoemulsification and were examined with scanning electron microscopy (SEM) and TEM. Results: Exfoliation samples exhibited an overall more irregular apical surface of the lens epithelium compared to control aLCs. The height of LECs varied extensively. On the apical surface of LECs, amorphous, crystalline-like, or microgranular extracellular material and membranous, oval-shaped structures
\end{abstract}

karger@karger.com

(c) 2020 S. Karger AG, Basel

www.karger.com/ore

Karger" were documented with SEM. All findings were connected to corresponding observations with TEM and were not correlated to the type of cataract. Conclusions: In XFS patients, the lens epithelial surface exhibited a highly irregular margin, with extracellular material covering the apical membrane of LECs. We suggest that XFS probably causes both epithelial and lens fiber degeneration which, during CCC and mechanical extraction of the aLC from the lens cortex, result in diverse alterations.

c) 2020 S. Karger AG, Basel

\section{Introduction}

Exfoliation syndrome (XFS) is an age-related disorder with a relatively high prevalence in Greece [1-7], which is etiopathogenetically connected with glaucoma [8]. It is also associated with cataract formation and increased surgical complications during cataract surgery [9-11].

XFS is characterized by the production and chronic accumulation of abnormal fibrillar material in many ocu-

K.N.S. and M.E.M. contributed equally to this work. 
lar and extraocular tissues [8]. Clinically, it most commonly appears as white deposits of the material on the anterior lens surface [8]. In XFS patients, ultrastructural studies of the anterior lens capsule (aLC), which is comprised of the basement membrane and the lens epithelium, have demonstrated exfoliation fibrils deposited on the free surface of the basement membrane, towards the anterior chamber $[8,12,13]$.

We recently studied aLCs of XFS patients with transmission electron microscopy (TEM) for the first time in a Greek population. We have already reported novel TEM observations such as severe abnormalities of the lens epithelial cells (LECs) [14], the presence of exfoliation fibrils within the basement membrane of the aLC [15], and the presence of a new, not previously described material on the apical side of the lens epithelium, towards the lens fibers [16]. It is mainly the latter ultrastructural alterations that seem to be related to easier hydrodissection in XFS patients, as described lately [17].

Earlier scanning electron microscopy (SEM) studies documented exfoliation fibrillar material on the basement membrane of aLCs, reporting that the lens capsule itself and epithelium appeared normal [8, 18-21]. Most of the studies were conducted before phacoemulsification was established in cataract surgery; the surgical technique used for obtaining the aLC was either intracapsular or extracapsular cataract extraction and often the aLC and the underlying lens fibers were examined as a single structure [18-21]. To our knowledge, this is the first SEM study in XFS, in which the aLC specimens were obtained with continuous curvilinear capsulorrhexis (CCC) and were studied separately, providing the opportunity to observe the apical membrane of the LECs.

The purpose of the present study was to use SEM to investigate cataractous aLC surfaces in patients with and without XFS obtained through phacoemulsification. Additionally, we aimed to correlate observations between SEM and TEM.

\section{Materials and Methods}

Fourteen patients with senile cataract, older than 60 years, who visited the 2nd Eye Department of the Medical School of Aristotle University in Thessaloniki, Greece, were included in the study. Seven of them were diagnosed with XFS. The exfoliation material was observed on their anterior lens surfaces in slit-lamp examination. The other 7 cataract patients constituted the control group of the study.

The aLC specimens, which consist of the basement membrane and the lens epithelium, were obtained from patients during uneventful phacoemulsification by the same surgeon (I.T.T.) at $\mathrm{Pa}$ -
Table 1. Statistical analysis between patients with and without XFS

\begin{tabular}{lccc}
\hline & XFS group & $\begin{array}{l}\text { Control } \\
\text { group }\end{array}$ & $p$ value \\
\hline $\begin{array}{l}\text { Mean age (SD), years } \\
\text { Gender, } n\end{array} \quad$ M4.9(8.4) & $81.1(6.6)$ & 0.168 \\
$\quad$ Male & 4 & 3 & \\
$\quad$ Female & 3 & 4 & 1.000 \\
Biomicroscopic type of & & & \\
$\quad$ cataract, $n$ & 2 & 3 & \\
$\quad$ Cortical & 3 & 3 & \\
$\quad$ Nuclear & 2 & 1 & 1.000 \\
$\quad$ Posterior subcapsular & 4 & 0 & 0.070 \\
Glaucoma, $n$ & 2 & 1 & 1.000 \\
Diabetes mellitus, $n$ & & & \\
\hline
\end{tabular}

pageorgiou University Hospital in Thessaloniki. For each patient, CCC was performed and a circular portion of the central aLC, measuring 5-5.5 mm, was carefully removed. In the operating room, the tissue was immediately immersed in a neutral-buffered $3 \%$ glutaraldehyde and then it was transferred at the laboratory of Histology and Embryology, Aristotle University of Thessaloniki. All aLCs were fixed in glutaraldehyde for $90 \mathrm{~min}$ and then each one was cut in 2 halves. All specimens were post-fixated in $2 \% \mathrm{OsO}_{4}$ and were subsequently dehydrated in increasing concentrations of ethanol.

One half of each specimen was embedded in Epon 812. Ultrathin sections $(30-50 \mu \mathrm{m})$ were stained with uranyl-acetate and lead-citrate and were examined using a JEM-1011 (JEOL Inc., Peabody, MA, USA) transmission electron microscope. Six different areas of the aLCs with a total of at least 25 cells were examined in each case with TEM. The remaining halves of the specimens were allowed to dry after dehydration. They were then sputter-coated with carbon and were finally observed under an SEM (JEOL JSM$6390 \mathrm{LV}$ ) at an accelerating voltage of $20 \mathrm{kV}$. In both TEM and SEM, each specimen was examined by 2 independent pathologists (M.E.M., S.M.) in a "blind" process, without being informed about the presence or not of XFS in each patient.

Standard statistical methods were used for the descriptive statistics. The normality of the data distribution was tested according to the Shapiro-Wilk test. The Student $t$ test, $\chi^{2}$ test, and Fisher's exact test were chosen for comparisons between groups. The hypothesis of the equality of means was discarded when the probability $(p)$ of a type I error was $<5 \%$. The statistical tests were twotailed. Analyses were performed using SPSS Statistics for Windows, version 23.0 (IBM Corp., Armonk, NY, USA).

\section{Results}

The demographic data of the patients included in the study are shown in Table 1. In all cases of the XFS group, the typical fibrils of the syndrome were observed on the surface of the basement membranes, towards the anterior chamber, both with SEM (Fig. 1d, e) and TEM (Fig. 1f). 
Fig. 1. Images of an aLC from a patient with XFS. a An SEM image $(\times 500)$ of the folded aLC, where both the lens epithelium (e) and the surface of the basement membrane (BM) are visible. XFS fibrillar material is observed upon the basement membrane's surface. Arrows indicate amorphous crystalline-like material on the apical capsular surface. SEM images $\times 1,200$ (b) and $\times 1,000$ (c). Areas with "fried egg-like" LECs neighbor other areas of taller, possibly swollen LECs. The lateral cell connections and the cell boundaries are visible. b A microgranular material, measuring $1-2 \mu \mathrm{m}$, is observed on the apical capsular surface (in the upper right quarter). c Cell protrusions of the taller cells cover adjacent LECs. SEM images $\times 3,000$ (d) and $\times 1,000(\mathbf{e})$. The surface of the basement membrane appears with aggregates of exfoliation material. $\mathbf{f} \mathrm{A}$ TEM micrograph $(\times 8,000)$ of the same patient, with exfoliation fibrils upon the BM. ac, anterior chamber; fm, fibrillar material.
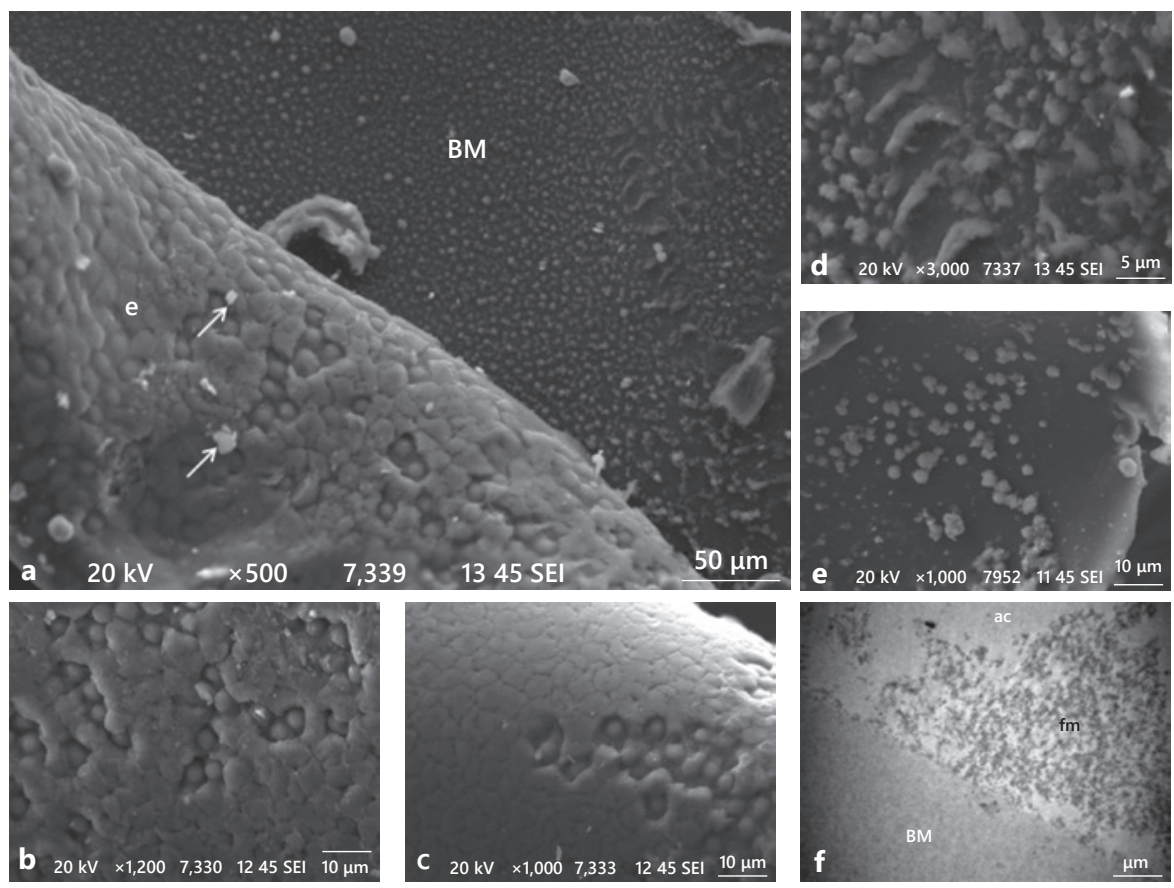
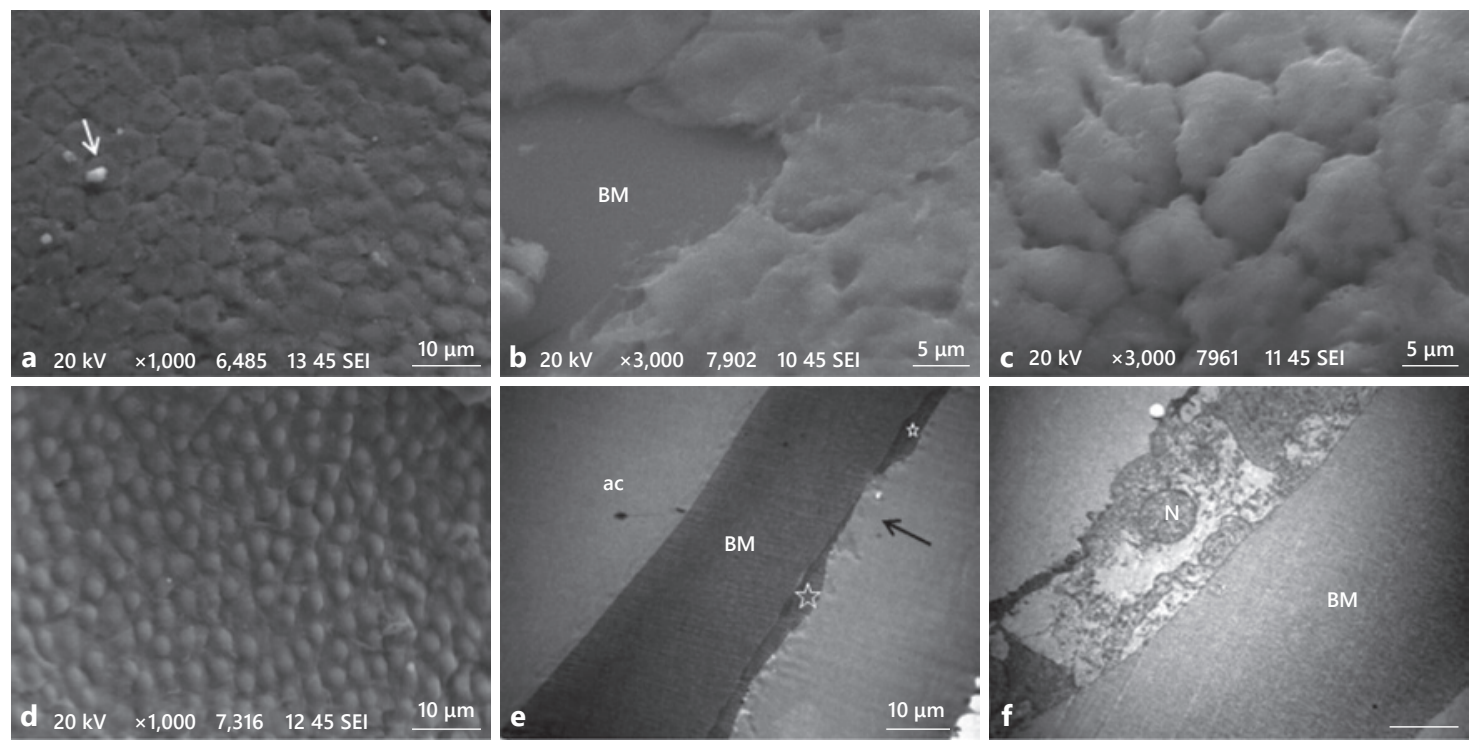

Fig. 2. Micrographs of aLCs from 4 different control patients with senile cataract. a An SEM image $(\times 1,000)$ of rather flat LECs, with tight connections between each other. The white arrow indicates crystalline-like material on the apical capsular surface. b An SEM image $(\times 3,000)$ of an aLC where the LECs are completely absent, rendering the basement membrane visible. c An SEM image $(\times 3,000)$ with LECs appearing taller and edematous. The cell membrane connections on their higher parts are clearly visible. d An SEM image $(\times 1,000)$ of "fried egg-like" LECs, where the nuclei cause protrusions on cell membranes. e A TEM micrograph $(\times 3,000)$ of the same patient as in $\mathbf{b}$. A gap in lens epithelium is indicated with the black arrow and the neighboring LECs appear very flat (stars). f A TEM micrograph $(\times 5,000)$ of the same patient as in c. Extensive intracellular edema is visible. BM, basement membrane; $\mathrm{N}$, nucleus; ac, anterior chamber. 
Fig. 3. a An SEM image $(\times 500)$ of another control aLC with rather sparse LECs and areas with the basement membrane visible. b An SEM image $(\times 2,000)$ of the same patient as $\mathbf{a}$, where the anchor-like protrusions towards the basement membrane $(\mathrm{BM})$ are obvious. c An SEM image $(\times 3,500)$ of aLC from the same XFS patient as in Figure 1. LECs of various heights are demonstrated as a single pseudostratified epithelium. Taller cells seem to extend small anchors over the smaller "fried egg-like" cells. d A TEM micrograph $(\times 5,000)$ of the same patient as in c. An electron-denser cytoplasmic process, indicated with an asterisk, covers the adjacent, more damaged LECs, giving the impression of multilayering.
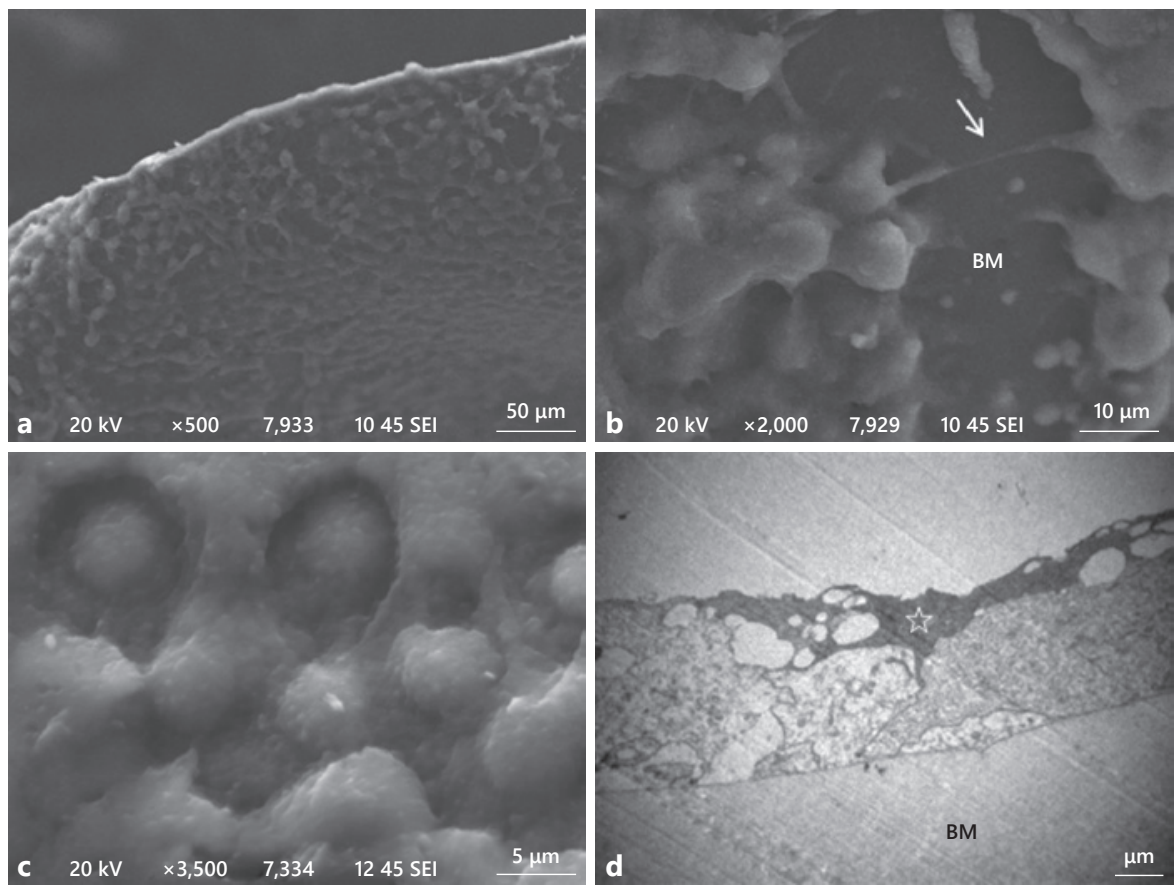

\section{SEM Observations}

The three-dimensional morphology of the aLCs was observed by means of SEM. In all cases, the epithelial cells formed a single layer, lying on the basement membrane. They were usually polygonal, in proximity to each other, with tight connections. In some areas, however, they were fewer or even absent, rendering the basement membrane beneath them visible (Fig. 2b, 3a, b, 4e).

The cells appeared in various shapes but were most commonly rather flat, often bearing many microvilli on their apical surface (Fig. 2). The nuclei of the flat cells were usually indirectly visible causing a small protrusion on the cell membrane. The appearance of the free surface of the cells in these areas reminded us of fried eggs (Fig. 2d). In other areas the free surface of the flat cells often appeared without any lumps or indentations (Fig. 2a). In 1 XFS patient a few LECs appeared with a wrinkled apical cell membrane (Fig. 5d).

The cells very often appeared taller and edematous (Fig. 1a-c, 3c). The cell membrane connections on their higher parts were clearly visible (Fig. 2c). When these cells were located near flat cells, their shapes were easier to distinguish and they were obviously taller, probably cuboid or cylindrical in shape (Fig. 3c). The cells occasionally presented characteristics of a single pseudostratified epithelium (Fig. 3). In areas with fewer cells present, we had the opportunity to observe their lateral surfaces as well.
Anchor-like protrusions were often detected, extending towards other cells, sometimes covering them, or towards the basement membrane (Fig. 2b, 3a, b).

While observing the apical surface of LECs, towards the lens cortex, the cell boundaries and the connections on their upper parts were usually visible. In 3 out of 7 XFS cases the apical capsular surface in some areas appeared with no demarcations to allow delimitation of cell boundaries. It seemed as if there was a membranous cover over the cell surfaces preventing visualization (Fig. $4 \mathrm{a}, \mathrm{b}$ ).

In 6 of the 7 XFS cases and in 2 of the 7 control patients, a microgranular material was visible on the apical capsular surface as well (Fig. 1b, 4b, d, e). The granules usually measured 1-2 $\mu \mathrm{m}$, but sometimes reached $4-5 \mu \mathrm{m}$. They were found dispersed all over the surface and very often formed smaller or larger aggregates. The microgranules were not always in touch with the epithelial cells lying beneath them; instead, they seemed to "float" over them. In both control cases and in 1 of the XFS cases where the microgranules were observed, their presence was restricted in only a small, specific area of the studied capsule. In 4 out of 7 XFS patients and in 2 out of 7 control patients, an amorphous material with a crystalline appearance, forming variously shaped structures, without specific orientation or density, was observed on the apical capsular surface (Fig. 1a, 2a). 

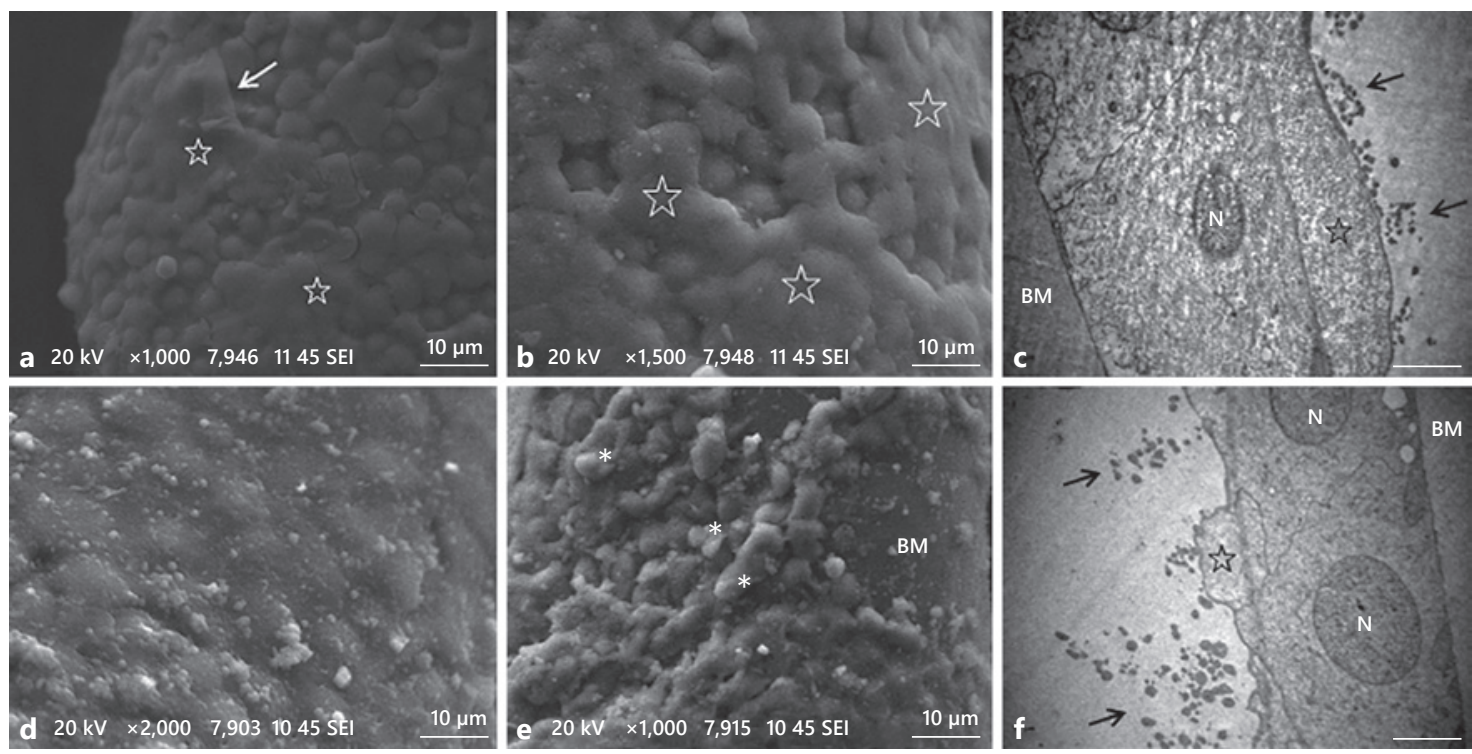

Fig. 4. SEM photographs $\times 1,000(\mathbf{a})$ and $\times 1,500(\mathbf{b})$ of another patient from the XFS group. Membranous structures cover the "fried egg-like" LEC surfaces (stars). The cell boundaries are hidden underneath these covers. a The arrow points to a flap of this membranous cover, revealing the underneath cells. b On the left, microgranular material is observed upon the membranous cover. c A TEM micrograph of the same XFS patient $(\times 10,000)$. Arrows indicate unbound, microgranular, electron-dense material over a membranous structure (star), which is attached to the lens epithelium. SEM images $\times 2,000(\mathbf{d})$ and $\times 1,000$ (e) of another patient

In 1 case from the control group and 3 from the XFS group, osmiophobic, smooth, oval-shaped structures were detected on the apical capsular surface (Fig. 4e, 5a-c, e). These structures were smaller than the cells, measuring 4-7 $\mu \mathrm{m}$ and were usually oriented in a similar way, so that their long axes were parallel to each other. The structures were distributed all over the surface but usually appeared in small groups. They seemed to be in contact with the cell surfaces, sometimes even giving the impression that they were emerging from them.

The most representative SEM microphotographs for each patient included in the present study are available in the online supplementary material (for all online suppl. material, see www.karger.com/doi/10.1159/000508631).

\section{TEM Observations}

TEM examination revealed similar findings to our previous studies $[14,16]$. An unbound, electron-dense, microgranular, spherical material was recorded in 3 out of 7 XFS aLCs (Fig. 4c, f, 5f). On the apical side of the LECs, membranous structures of lower electron density attached to the LECs (Fig. 4c, f) and larger formations of with XFS. Microgranules measured 1-2 $\mu \mathrm{m}$, occasionally forming aggregates, are dispersed all over the surface of lens epithelium. They appear either in touch with the LECs lying beneath them or "floating" over them. e Microgranules seem to cover the revealed basement membrane (BM). Additionally, osmiophobic, smooth, oval-shaped structures (white asterisks) are detected on the apical, capsular surface. $\mathbf{f}$ A TEM micrograph $(\times 5,000)$ of the same XFS patient as in $\mathbf{d}$ and $\mathbf{e}$. Microgranules (arrows) and a smaller membranous structure (star) are observed. N, nucleus.

higher electron density, resembling cellular parts being detached from LECs (Fig. 5f), were documented in 2 XFS patients.

Abnormalities of the LECs, such as intracellular and extracellular edema, transparent vacuoles, ruptures of the apical cell membrane, completely destroyed epithelial cells, "multilayering," loss of the cubic shape of cells, and cells with varying heights, were observed in both groups (Fig. 2e, f, 3d, 5f). These lesions were more severe and extensive in the XFS patients. Both SEM and TEM findings did not differ among the different types of cataract (cortical, nuclear, posterior subcapsular) in both the control and XFS groups.

\section{Discussion}

In the control group the apical surface of the lens epithelium, as demonstrated with SEM, was rather smooth, bearing cells with similar characteristics. This is in accordance with results described in previous SEM studies of cataractous aLCs $[22,23]$. 

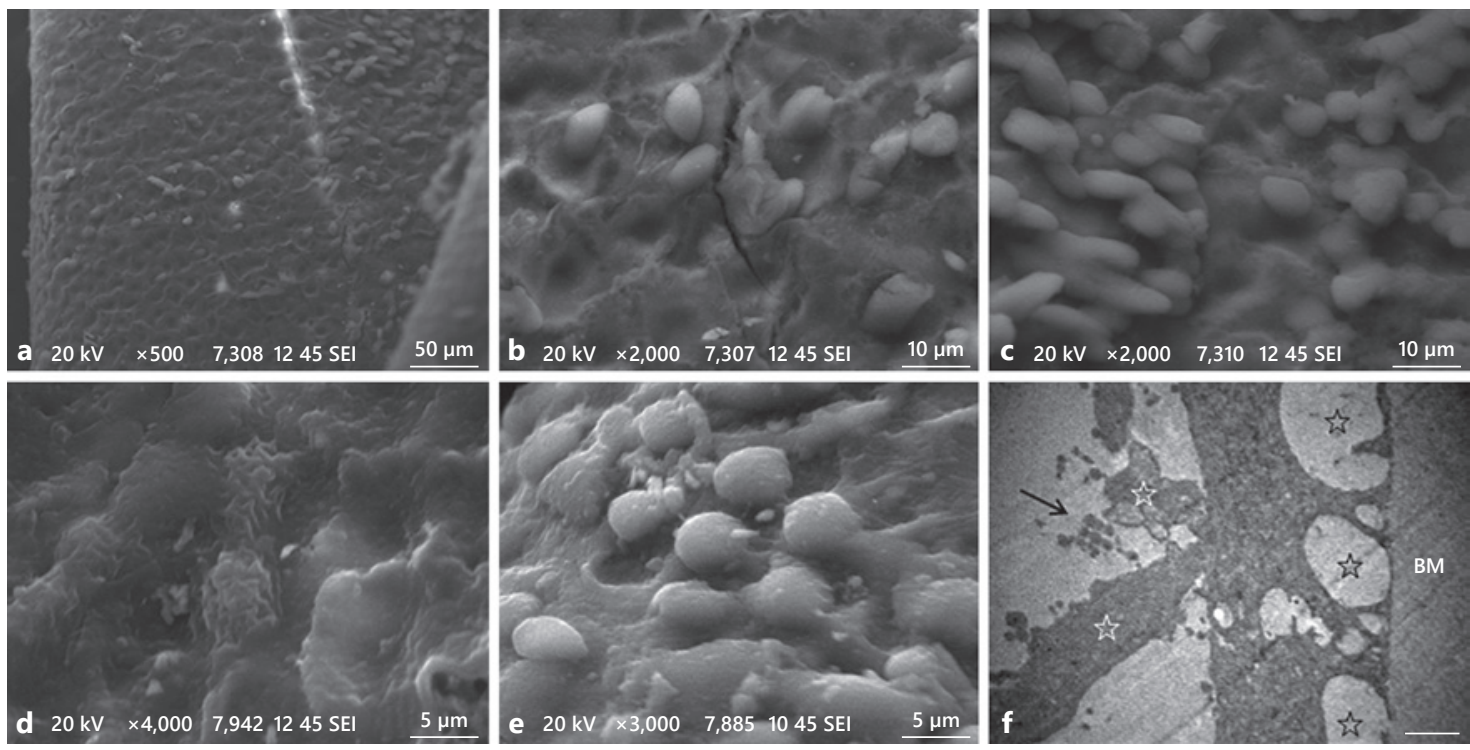

Fig. 5. SEM images $\times 500(\mathbf{a})$ and $\times 2,000(\mathbf{b}, \mathbf{c})$ of another XFS patient with mature senile cataract. Indentations on LECs are observed all over the aLC. Osmiophobic, smooth, oval-shaped structures are detected on the apical, capsular surface. These structures appear smaller than the cells, measuring 4-7 $\mu \mathrm{m}$. c The structures appear in groups and are oriented in a similar way, so that their long axes are parallel to each other. They seem to be in contact with the LEC surfaces, frequently giving the impression that they are emerging from them. d An SEM image $(\times 4,000)$ of another XFS
aLC. The 2 central LECs have a morphological appearance resembling apoptosis. e An SEM image of another patient with XFS. The osmiophobic, oval-shaped structures are covered by microgranular material. $f$ A TEM micrograph $(\times 8,000)$ of the same patient as in e. Transparent vacuoles are observed in lens epithelium (black stars). The arrow indicates the unbound, microgranular material, which covers the larger electron-dense formations (white stars). These formations seem to detach from the LECs. BM, basement membrane.
Areas with fewer or absent LECs were demonstrated by SEM in both groups, revealing anchor-like protrusions upon the basement membrane. TEM examination confirmed both the absence of LECs and the presence of cell cytoplasmic protrusions, in an attempt to compensate for cell loss. These alterations have been attributed to cataract pathology $[14,24]$.

The image of wrinkled apical membrane described in SEM resembles buckling of the actin cortex during bleb retraction, indicating apoptotic cells [25]. Apoptotic LECs were observed in our previous TEM research [16] but were not detected in the present study with TEM. Under normal conditions, apoptosis is an impressively rapid procedure lasting from 2 to $24 \mathrm{~h}$. As a result, at a single time point only a few cells are undergoing apoptosis; therefore, detecting even a single apoptotic cell by TEM may be difficult [26]. Apoptosis has previously been related to both cataract and XFS [27-29].

In the XFS group, SEM examination revealed a variation in the height of LECs. This finding was verified by our TEM observations and resulted in an irregular appearance of the lens epithelial surface.

Lens Epithelial Surface Disorders in Exfoliation Syndrome
Joo et al. [30] described LECs as polygonal cells with microvilli and fiber remnants of variable diameter and irregular directions on their surface. This description is in accordance with our findings. In our sample, LECs usually appeared polygonal with microvilli. Amorphous crystalline-like material was detected in both groups over the lens epithelium surface, but more frequently in XFS patients.

The microgranular material that was described with SEM, detected on the apical surface of mainly the XFS samples, seems to match the unbound microgranular material observed with TEM. The same TEM findings were described in detail in own previous work [16]. The membranous cover detected over the cell surfaces in SEM of XFS patients may be correlated with the membranous structures described in TEM, attached onto the LECs.

The osmiophobic, smooth, oval-shaped structures we detected, mainly in XFS, may have similarities with the bulges described in a study of intumescent white cataract, although the latter were spherical [31]. Moreover, none of our patients had this type of cataract. In another study, structures similar to ours were characterized as swollen

Ophthalmic Res 2021;64:216-223 
and distorted nuclei [32]. In our specimens the structures were usually situated in a higher level than the epithelial cells, which seemed intact, weakening this possibility. The structures also reminded us of the globules described by Jensen and Laursen [33] in the lens cortex, often on the epitheliocortical borders, which were related to degeneration of the fibers. Such globular formations are reported to appear when fiber degeneration occurs [34].

Despite the limitation of a rather small sample in the present study, the differences between the 2 groups were obvious. We tried to overcome the limitation of objectivity during electron microscopy examination by assigning both SEM and TEM evaluation of all specimens to 2 independent "blind" pathologists, who were not informed about the presence or absence of XFS in each patient, and their records were in agreement.

Overall, the described findings observed on the apical surface of LECs are located on the epithelial-lens fiber interface. It is reasonable to conclude that these materials may arise either from the LECs or from the lens fibers. It has already been reported that the epithelial cells exhibit occasionally severe degenerative alterations [14]. We can therefore suggest that the described material, or maybe part of it, arises from the lens epithelium. On the other hand, it should be considered that lens fiber remnants and degeneration have also been reported in SEM studies $[33,30]$. The membranous structures, the larger, electron-denser formations, and the microgranular and crystalline-like material observed each exhibited a different electron density. If they do originate from lens fibers, the variety in their appearance could be related or could be analogous to the degree of fiber degeneration.

\section{Conclusion}

We suggest that the degeneration of both lens epithelium and lens fibers during the mechanical extraction of aLCs from the underlying lens cortex with CCC probably results in the ultrastructural materials described in the present study. Overall, these findings are either more ob- vious or only appear in XFS patients, indicating that the lens epithelium and the underlying lens fibers are generally more degenerated in these patients. These findings could also justify the ease of hydrodissection in XFS patients [17]. Pathogenetic mechanisms influencing the physiology of the lens epithelial-fiber border are probably responsible for the observed degeneration and should be further investigated.

\section{Acknowledgements}

We wish to thank Oikonomidis Stavros and Moula Anastasia for their technical assistance with the scanning electron microscope and the transmission electron microscope, respectively.

\section{Statement of Ethics}

Written informed consent was obtained from all patients. The research was approved by the Ethical Committee of the Aristotle University of Thessaloniki (No. 5.193/06-07-2016) and the Hellenic Data Protection Authority (approval No. ГN/E $\Xi / 1445$ 1/27.04.2015), in accordance with the World Medical Association Declaration of Helsinki.

\section{Disclosure Statement}

The authors have no conflicts of interest to declare.

\section{Funding Sources}

There are no funding sources to declare.

\section{Author Contributions}

K.N.S. and M.E.M.: conception and design. K.N.S., M.E.M., S.M., I.T.T., N.Z., and K.K.-K.: acquisition, analysis, and interpretation of data. K.N.S., M.E.M., and S.M.: writing - original draft preparation. I.T.T., N.Z., and K.K.-K. writing - review and editing. All authors gave final approval of the version to be published and agreement to be accountable for all aspects of the work.

\section{References}

1 Forsius H. Prevalence of pseudoexfoliation of the lens in Finns, Lapps, Icelanders, Eskimos, and Russians. Trans Ophthalmol Soc UK. 1979 Jul;99(2):296-8.

2 Forsius H. Exfoliation syndrome in various ethnic populations. Acta Ophthalmol Suppl. 1988; 184:71-85.
3 Krause U, Alanko HI, Kärnä J, Miettinen R, Larmi T, Jaanio E, et al. Prevalence of exfoliation syndrome in Finland. Acta Ophthalmol Suppl. 1988;184:120-2.

4 Stefaniotou M, Petroutsos G, Psilas K. The frequency of pseudoexfoliation in a region of Greece (Epirus). Acta Ophthalmol. 1990 Jun; 68(3):307-9.
Sorkou/Manthou/Meditskou/ Tsinopoulos/Ziakas/Kouzi-Koliakou 
5 Kozobolis VP, Papatzanaki M, Vlachonikolis IG, Pallikaris IG, Tsambarlakis IG. Epidemiology of pseudoexfoliation in the island of Crete (Greece). Acta Ophthalmol Scand. 1997 Dec;75(6):726-9.

6 Andrikopoulos GK, Mela EK, Georgakopoulos CD, Papadopoulos GE, Damelou AN, Alexopoulos DK, et al. Pseudoexfoliation syndrome prevalence in Greek patients with cataract and its association to glaucoma and coronary artery disease. Eye. 2009 Feb;23(2): $442-7$.

7 Anastasopoulos E, Topouzis F, Wilson MR, Harris A, Pappas T, Yu F, et al. Characteristics of pseudoexfoliation in the Thessaloniki Eye Study. J Glaucoma. 2011 Mar;20(3):160-6.

8 Ritch R, Schlötzer-Schrehardt U. Exfoliation syndrome. Surv Ophthalmol. 2001 Jan-Feb; 45(4):265-315.

9 Seland JH, Chylack LT Jr. Cataracts in the exfoliation syndrome (fibrillopathia epitheliocapsularis). Trans Ophthalmol Soc UK. 1982; 102(Pt 3):375-9.

10 Puska P, Tarkkanen A. Exfoliation syndrome as a risk factor for cataract development: fiveyear follow-up of lens opacities in exfoliation syndrome. J Cataract Refract Surg. 2001 Dec; 27(12):1992-8

11 Bialasiewicz AA, Wali U, Shenoy R, Al-Saeidi R. Cataract patients with pseudoexfoliation (PEX) syndrome among a population with high prevalence of PEX. Clinical findings and morphological and surgical characteristics. Ophthalmologe. 2005 Dec;102(12):1181-5. German.

12 Ruotsalainen J, Tarkkanen A. Capsule thickness of cataractous lenses with and without exfoliation syndrome. Acta Ophthalmol. 1987 Aug;65(4):444-9.

13 Hollo G, Konstas AG, editors. Exfoliation syndrome and exfoliative glaucoma. 2 nd ed. Savona: European Glaucoma Society; 2012.

14 Sorkou KN, Manthou ME, Ziakas N, Tsaousis KT, Tsinopoulos IT; SoultanaMeditskou. Severe abnormalities of lens epithelial cells in exfoliation syndrome: a transmission electron microscopy study of patients with age-related cataract. Medicina. 2019 May;55(6):E235.
15 Sorkou KN, Manthou ME, Meditskou S, Ziakas N, Tsinopoulos IT. Exfoliation fibrils within the basement membrane of anterior lens capsule: a transmission electron microscopy study. Curr Eye Res. 2019 Aug;44(8): $882-6$.

16 Sorkou KN, Manthou ME, Tsaousis KT, Brazitikos P, Tsinopoulos IT. Transmission electron microscopy study of undescribed material at the anterior lens capsule in exfoliation syndrome. Graefes Arch Clin Exp Ophthalmol. 2018 Sep;256(9):1631-7.

17 Sorkou K, Tsinopoulos IT, Tsaousis KT, Karamitsos A, Meditskou S, Ziakas N, et al. Ease of hydrodissection during phacoemulsification: a comparison between patients with and without exfoliation syndrome. Ophthalmic Res. 2020, Online ahead of print.

18 Ashton N, Shakib M, Collyer R, Blach R. Electron microscopic study of pseudo-exfoliation of the lens capsule. I. Lens capsule and zonular fibers. Invest Ophthalmol. 1965 Apr;4:14153.

19 Dark AJ, Streeten BW, Cornwall CC. Pseudoexfoliative disease of the lens: a study in electron microscopy and histochemistry. $\mathrm{Br} \mathrm{J}$ Ophthalmol. 1977 Jul;61(7):462-72.

20 Seland JH. The ultrastructural changes in the exfoliation syndrome. Acta Ophthalmol Suppl. 1988;184:28-34.

21 Dark AJ, Streeten BW. Precapsular film on the aging human lens: precursor of pseudoexfoliation? Br J Ophthalmol. 1990 Dec;74(12): $717-22$.

22 Andjelic S, Drašlar K, Hvala A, Lopic N, Strancar J, Hawlina M. Anterior lens epithelial cells attachment to the basal lamina. Acta Ophthalmol. 2016 May;94(3):e183-8.

23 Osnes-Ringen $\varnothing$, Berg KH, Moe MC, Zetterström C, Røger M, Nicolaissen B. Cell death pattern in lens epithelium of cataract patients. Acta Ophthalmol. 2016 Aug;94(5):514-20.
24 Sargon MF, Celik HH, Orhan M. Electron microscopy of the senile changes in lens epithelium. Okajimas Folia Anat Jpn. 1997 Aug; 74(2-3):75-9.

25 Charras GT. A short history of blebbing. J Microsc. 2008 Sep;231(3):466-78.

26 Saraste A, Pulkki K. Morphologic and biochemical hallmarks of apoptosis. Cardiovasc Res. 2000 Feb;45(3):528-37.

27 Harocopos GJ, Alvares KM, Kolker AE, Beebe DC. Human age-related cataract and lens epithelial cell death. Invest Ophthalmol Vis Sci. 1998 Dec;39(13):2696-706.

28 Charakidas A, Kalogeraki A, Tsilimbaris M, Koukoulomatis P, Brouzas D, Delides G. Lens epithelial apoptosis and cell proliferation in human age-related cortical cataract. Eur J Ophthalmol. 2005 Mar-Apr;15(2):213-20.

29 Oltulu P, Oltulu R. The Association of Cataract and Lens Epithelial Cell Apoptosis in $\mathrm{Pa}$ tients with Pseudoexfoliation Syndrome. Curr Eye Res. 2018 Mar;43(3):300-3.

30 Joo CK, Lee EH, Kim JC, Kim YH, Lee JH, Kim JT, et al. Degeneration and transdifferentiation of human lens epithelial cells in nuclear and anterior polar cataracts. J Cataract Refract Surg. 1999 May;25(5):652-8.

31 Andjelic S, Draslar K, Hvala A, Hawlina M. Anterior lens epithelium in intumescent white cataracts - scanning and transmission electron microscopy study. Graefes Arch Clin Exp Ophthalmol. 2016 Feb;254(2):269-76.

32 Los LI, Jongebloed WL, Worst JG. Lens-capsule material of human and animal origin, studied by SEM. Doc Ophthalmol. 1989 Aug; 72(3-4):357-65.

33 Jensen OA, Laursen AB. Human senile cataract. Light- and electron-microscopic studies of the morphology of the anterior lens structures, with special reference of anterior capsular/subcapsular opacity. Acta Ophthalmol. 1980 Aug;58(4):481-95.

34 Jongebloed WL, Kalicharan D, Los LI, van der Veen G, Worst JG. A combined scanning and transmission electronmicroscopic investigation of human (secondary) cataract material. Doc Ophthalmol. 1991;78(3-4):325-34. 